\title{
INCREMENTO NA DENSIDADE DE PLANTAS: UMA ALTERNATIVA PARA AUMENTAR O RENDIMENTO DE GRÃOS DE MILHO EM REGIÕES DE CURTA ESTAÇÃO ESTIVAL DE CRESCIMENTO
}

\author{
INCREMENT ON PLANT DENSITY: AN ALTERNATIVE TO IMPROVE MAIZE \\ GRAIN YIELD IN SHORT GROWING SEASON REGIONS
}

\author{
Milton Luiz de Almeida ${ }^{1}$, Aldo Merotto Junior ${ }^{2}$, Luís Sangoi ${ }^{3}$, \\ Márcio Ender ${ }^{4}$, Altamir Frederico Guidolin ${ }^{4}$.
}

\section{RESUMO}

\begin{abstract}
O surgimento de novos cultivares de milho, de ciclo mais curto, estatura reduzida, menor número de folhas e folhas mais eretas aumentou o potencial de resposta da cultura à densidade de plantas. Essa tendência pode ser acentuada nos planaltos do Sul do Brasil, que apresentam temperatura média nos meses mais quentes inferiores a $22^{\circ} \mathrm{C}$, o que resulta em menor estação estival de crescimento. Quatro experimentos foram conduzidos objetivando avaliar a viabilidade de se trabalhar com densidade de plantas maiores do que as atualmente recomendadas para esta região, como uma forma de aumentar o rendimento de grãos. Nestes experimentos, submeteram-se os híbridos Cargill 901 e XL 370 a uma população que variou de 37.000 a $100.000 \mathrm{pl} \mathrm{ha} \mathrm{h}^{-1}$, sob diferentes situações de manejo. Em três dos quatro experimentos realizados, o uso de densidade de plantas superior a $60.000 \mathrm{plha}^{-1}$ maximizou o rendimento de grãos. A maior competição intraespecífica verificada nas densidades mais elevadas não reduziu drasticamente o número de espigas por planta, o que contribuiu para a melhor adaptação da cultura a densidades elevadas. Dessa forma, para locais com estação estival de crescimento mais curta, o uso de cultivares precoces, de menor porte, pode ser acompanhado pelo incremento na densidade para valores compreendidos entre 65.000 e $80.000 \mathrm{pl} \mathrm{ha}^{-1}$. Isso é possível desde que se tenha bom nível de fertilidade no solo, boa disponibilidade hídrica e cultivares resistentes ao acamamento.
\end{abstract}

Palavras-chave: Zea mays, L., densidade de plantas, precocidade, rendimento de grãos.

\section{SUMMARY}

The development of earlier hybrids, with shorter plant height, lower leaf number and upright leaves has increased maize potential adaptability to withstand high plant densities. This trend may be emphasized on the high lands of Southern Brazil due to their mild Spring and Summer temperatures and shorter maize growing season. Four trials were carried out, aiming to investigate the viability of using higher than recommended plant populations, as an alternative to improve grain yield. The maize hybrids Cargill 901 and XL 370 were evaluated at several plant populations, ranging from 37000 to $100000 \mathrm{pl} \mathrm{ha} \mathrm{h}^{-1}$, under different management situations. In three out of four experiments, plant populations above 60000pl ha $\mathrm{h}^{-1}$ maximized grain yield. The greater competition among individuals verified at high plant populations did not decrease substantially the number of ears per plant, which contributed to improve maize adaptation to high plant densities. Therefore, for regions with a short growing season, the use of early small stature maize hybrids may be accompanied by an increment in plant population up to a value varying between 65000 and $80000 \mathrm{pl} \mathrm{ha} \mathrm{h}^{-1}$. This is conceivable as long as there is adequate soil fertility, water availability and stem lodging resistant genotypes.

Key words: Zea mays, L., plant density, earlyness, grain yield.

\section{INTRODUÇÃO}

A interação entre as plantas de uma comunidade induz a mudanças morfológicas e fisiológicas, que são importantes para a determinação do potencial produtivo das culturas. As respostas à densidade de plantas incluem mudanças na arquitetura da comunidade, no crescimento, no desenvolvimento e na absorção e partição de assimilados

\footnotetext{
${ }^{1}$ Engenheiro Agrônomo, Doutor, Professor da Faculdade de Agronomia da Universidade do Estado de Santa Catarina (UDESC), CP 281, Lages/SC, CEP 88520-000, e-mail: a2mla@ cav.udesc.br. Pesquisador do CNPq.

${ }^{2}$ Engenheiro Agrônomo, MSc., Professor da Faculdade de Agronomia da Universidade Federal do Rio Grande do Sul.

${ }^{3}$ Engenheiro Agrônomo, PhD., Professor da Faculdade de Agronomia da UDESC.

${ }^{4}$ Engenheiro Agrônomo, MSc., Professor da Faculdade de Agronomia da UDESC. 
pelas plantas (CASAL et al., 1985). Dessa forma, os estudos conduzidos para identificar a densidade ideal de plantas objetivam determinar o número de plantas que é capaz de explorar de maneira mais eficiente e completa uma determinada área do solo (MUNDSTOCK, 1977; SILVA et al.,1995; ALMEIDA \& SANGOI, 1996; MERROTO Jr. $\boldsymbol{e t}$ al., 1997a; e MERROTO Jr. $\boldsymbol{e t}$ al., 1997b).

A exploração da elevada capacidade de rendimento de grãos de milho está relacionada ao contínuo desenvolvimento de técnicas que propiciem a maximização do seu potencial de exploração do ambiente. Com o surgimento de cultivares de ciclo mais curto, porte mais baixo, menor número de folhas e de folhas com angulação mais ereta, verificou-se um incremento no potencial de resposta da planta ao aumento da densidade (DWER $\boldsymbol{e t} \boldsymbol{a l}$., 1991; RUSSEL, 1991). A cultura do milho está entre aquelas que apresentaram maiores incrementos no seu rendimento de grãos nas últimas décadas (RUSSEL, 1991; TOLLENAR, 1991), entretanto, não se verificou aumento significativo na eficiência de acumulação de matéria seca nos grãos (SINCLAIR, 1998). A pequena alteração do índice de colheita (IC) indica que o ganho genético se deveu ao aumento da acumulação de matéria seca (MS) pela comunidade (TOLLENAR, 1991; SINCLAIR, 1998). Esse aumento na capacidade de acumulação de MS pela comunidade só foi possível porque as plantas suportam densidades maiores, sem diminuir drasticamente a emissão e a manutenção das espigas (TOLLENAR, 1991). Nesse sentido, PEIXOTO et al. (1997), trabalhando com híbridos modernos de ciclo curto e porte baixo, identificaram aumento linear no rendimento de grãos quando a densidade de plantas aumentou de 30 para 90 mil plha $^{-1}$. Essa resposta foi atribuída pelos autores à redução de apenas $6,7 \%$ no número de espigas por planta quando se aumentou a densidade de plantas. Por outro lado, trabalhando na mesma região com genótipos da década de 70, SILVA (1972) identificou reduções de até $35 \%$ no número de espigas por planta, quando a densidade foi aumentada de 30 para 90 milpl ha ${ }^{-1}$.

As temperaturas baixas verificadas no início da primavera nas regiões de elevada altitude do Sul do Brasil podem limitar o crescimento vegetativo e a produção de massa seca do milho (SANGOI, 1993). A produção de massa seca no período anterior ao florescimento representa o potencial que a comunidade pode investir na formação de grãos, respeitando suas características de IC (ALMEIDA $\boldsymbol{e} t$ $a l .$, 1998). Dessa forma, uma alternativa para compensar o menor crescimento vegetativo das plantas de milho, nesses casos, é a utilização de um maior número de plantas por unidade de área. Por outro lado, o menor crescimento das plantas e, conseqüentemente, das folhas tem implicações sobre a capacidade de produção de fotoassimilados pela cultura. Trabalhos realizados por JOHNSON et al.(1987), MORGAN et al.(1990), KASELE $\boldsymbol{e t}$ al. (1995) identificaram maior atividade fotossintética em folhas de menor tamanho, quando comparadas com folhas maiores. Esse incremento deveu-se ao aumento da densidade estomatal, do conteúdo de proteínas e de clorofila e, conseqüentemente, da taxa de assimilação de $\mathrm{CO}_{2}$. Assim, pode-se inferir que a disponibilidade climática das regiões de altitude do Sul do país, por determinarem a formação de folhas menores pelas plantas, pode permitir a formação de uma comunidade de plantas mais eficientes na acumulação de massa seca.

O potencial de resposta do milho ao aumento da densidade pode ser maior no Planalto Catarinense e em toda a região dos Campos Gerais, que abrange também o nordeste do Rio Grande do Sul e sudoeste do Paraná (FUNDAÇÃO INSTITUTO BRASILEIRO DE GEOGRAFIA ESTATÍSTICA, 1986). Tais áreas situam-se em altitudes superiores a 900m acima do nível do mar e possuem menor estação de crescimento para culturas estivais. A melhor exploração do potencial produtivo dos Campos Gerais passa pela avaliação da possibilidade de se utilizar densidades de plantas mais elevadas, como uma alternativa para compensar o menor crescimento vegetativo das plantas, principalmente no início do ciclo. Essa avaliação é enfatizada pelo lançamento de cultivares de menor ciclo, de baixa estatura de planta e de folhas menores e mais eretas. Esse tipo de arquitetura de planta faz com que a cultura tenha potencialmente melhores condições de apresentar um índice de espigas satisfatório, mesmo em populações elevadas. Assim, para esta região, o aumento do rendimento de grãos pode ser conseguido através de um maior número de espigas por área propiciado pelo uso de densidades mais elevadas de plantas.

O presente trabalho teve como objetivo avaliar a viabilidade de se trabalhar com densidades de plantas superiores às que são atualmente recomendadas para o Planalto Catarinense, como uma forma de aumentar o potencial produtivo das lavouras de milho.

\section{MATERIAL E MÉTODOS}

Foram conduzidos quatro experimentos no município de Lages, localizado no Planalto Sul de Santa Catarina. As coordenadas geográficas deste município são: latitude: $27^{\circ} 52^{\prime} \mathrm{S}$; longitude: $50^{\circ} 18^{\prime}$ 
W e altitude média de $930 \mathrm{~m}$. As condições climáticas se caracterizam por apresentar verões brandos, ou seja, com temperatura média inferior a $22^{\circ} \mathrm{C}$ nos meses mais quentes e com chuvas bem distribuídas nos meses de verão (média anual 1500mm) (EMPASC, 1978).

Além da densidade de plantas, foram testados outros fatores em cada experimento. No experimento 1 , testou-se a resposta de híbridos de milho de ciclo contrastantes, um de ciclo superprecoce (Cargill 901) e outro de ciclo precoce (XL 370). No experimento 2, avaliou-se o potencial de resposta das plantas à redução do espaçamento entre linhas. Já no experimento 3, trabalhou-se com diferentes métodos de controle de plantas daninhas, enquanto que no experimento 4, avaliou-se a interação entre densidade de plantas e a época de emergência de plantas adjacentes na linha. $\mathrm{O}$ cultivar utilizado nos experimentos 2, 3 e 4 foi a Cargill 901. Alguns detalhes sobre os tratamentos utilizados em cada experimento podem ser visualizados na tabela 1 .

Os experimentos 1, 2 e 3 foram conduzidos num cambissolo, húmico, álico de textura argilosa (UNIVERSIDADE FEDERAL DE SANTA MARIA, 1973). Já o experimento 4 foi conduzido numa terra bruna estruturada, húmica, álica de textura muito argilosa (UNIVERSIDADE FEDERAL DE SANTA MARIA, 1973). Em todos os experimentos, foi realizada análise prévia do solo. Através desta, corrigiu-se o pH do solo para 6,0 e adubou-se conforme recomendação da SOCIEDADE BRASILEIRA DE CIÊNNCIA DO SOLO - REGIÃO SUL (1989) para obtenção de rendimento de grãos superiores a $6.000 \mathrm{~kg} \mathrm{ha}^{-1}$. O preparo do solo foi convencional, com uma aração e duas gradagens de nivelamento. A adubação de manutenção foi efetuada em sulcos abertos previamente à semeadura. A semeadura de todos os experimentos foi realizada na primeira quinzena de novembro, nos anos de 1993, 1994, 1995, 1996, para os experimentos 1, 2, 3 e 4, respectivamente. Em cobertura, aplicaram-se duas doses de $60 \mathrm{~kg} / \mathrm{ha}$ de nitrogênio, quando as plantas apresentavam quatro e 10 folhas completamente expandidas.

O delineamento experimental utilizado foi o de blocos completamente casualizados com parcelas subdivididas com quatro repetições. Nos experimentos 1,2 e 3, alocaram-se nas parcelas principais os diferentes fatores (cultivares, espaçamento entre linhas e sistema de controle de plantas daninhas) e nas subparcelas, as densidades de plantas. Já no experimento 4, utilizaram-se as densidades de planta na parcela principal e os níveis de desuniformidade de emergência nas subparcelas. Em todos os experimentos, cada subparcela foi constituída por

Tabela 1 - Experimentos com densidade de plantas e diferentes fatores que afetam a resposta do milho à densidade. Faculdade de Agronomia CAV/UDESC, Lages, SC.

\begin{tabular}{|c|c|c|c|c|c|c|}
\hline $\begin{array}{l}\text { Número do } \\
\text { experimento }\end{array}$ & $\begin{array}{l}\text { Densidade } \\
\text { de plantas }\end{array}$ & Cultivares & $\begin{array}{l}\text { Espaçamento } \\
\text { entre linhas } \\
\text { (m) }\end{array}$ & Métodos de controle & $\begin{array}{c}\text { Desuniformidade de emergência } \\
\text { de plantas vizinhas }\end{array}$ & $\begin{array}{c}\text { Autores e ano de } \\
\text { execução- } \\
\text { publicação }\end{array}$ \\
\hline 1 & $\begin{array}{l}57.500 \\
71.500 \\
82.500\end{array}$ & $\begin{array}{l}\text { Cargil } 901 \\
\text { XL } 370\end{array}$ & 1,00 & $\begin{array}{l}\text { Herbicida em pré- } \\
\text { emergência + capina }\end{array}$ & & $\begin{array}{c}\text { ALMEIDA e } \\
\text { SANGOI } \\
(1993-94)-1996\end{array}$ \\
\hline 2 & $\begin{array}{l}37.000 \\
54.000 \\
64.000 \\
81.000\end{array}$ & Cargill 901 & $\begin{array}{l}0,75 \\
1,00\end{array}$ & $\begin{array}{l}\text { Herbicida em pré- } \\
\text { emergência + capina }\end{array}$ & & $\begin{array}{c}\text { MEROTTO Jr. } \\
\text { et al. }(1994-95 \mathrm{a}) \\
-1997\end{array}$ \\
\hline 3 & $\begin{array}{l}35.000 \\
50.000 \\
68.000 \\
80.000\end{array}$ & Cargill 901 & 0,90 & $\begin{array}{c}\text { Sem controle } \\
\text { Herbicida em pré- } \\
\text { emergência } \\
\text { Herbicida em pós- } \\
\text { emergência } \\
\text { Herbicida em pré+pós } \\
\text { Capina até o florescimento }\end{array}$ & & $\begin{array}{c}\text { MEROTTO Jr. } \\
\text { et al. }(1995-96 \mathrm{~b}) \\
-1997\end{array}$ \\
\hline 4 & $\begin{array}{l}40.000 \\
60.000 \\
80.000 \\
100.000\end{array}$ & Cargill 901 & 0,80 & $\begin{array}{l}\text { Herbicida em pré- } \\
\text { emergência + capina }\end{array}$ & $\begin{array}{l}\text { - Emergência uniforme } \\
\text { - Desuniformidade de } 12 \text { dias } \\
\text { (0-12-0-12-0-12) } \\
\text { - Desuniformidade de } 19 \text { dias } \\
\text { (0-19-0-19-0-19) } \\
\text { - Desuniformidade de } 12 \text { e } 19 \text { dias } \\
\text { (0-12-19-0-12-19 }\end{array}$ & $\begin{array}{l}\text { Em publicação } \\
(1996 / 97)\end{array}$ \\
\hline
\end{tabular}

Ciência Rural, v. 30, n. 1, 2000. 
quatro linhas de seis metros. A área útil das mesmas, na qual foi determinado o rendimento de grãos e seus componentes, englobou as duas linhas centrais, descartando meio metro em cada extremidade da linha. $\mathrm{O}$ rendimento de grãos determinado na área útil foi corrigido para um ha e para $13 \%$ de umidade.

O rendimento de grãos foi avaliado estatisticamente através da técnica da análise da variância. Quando alcançada significância estatística para o fator densidade de plantas, foi realizada a análise de regressão.

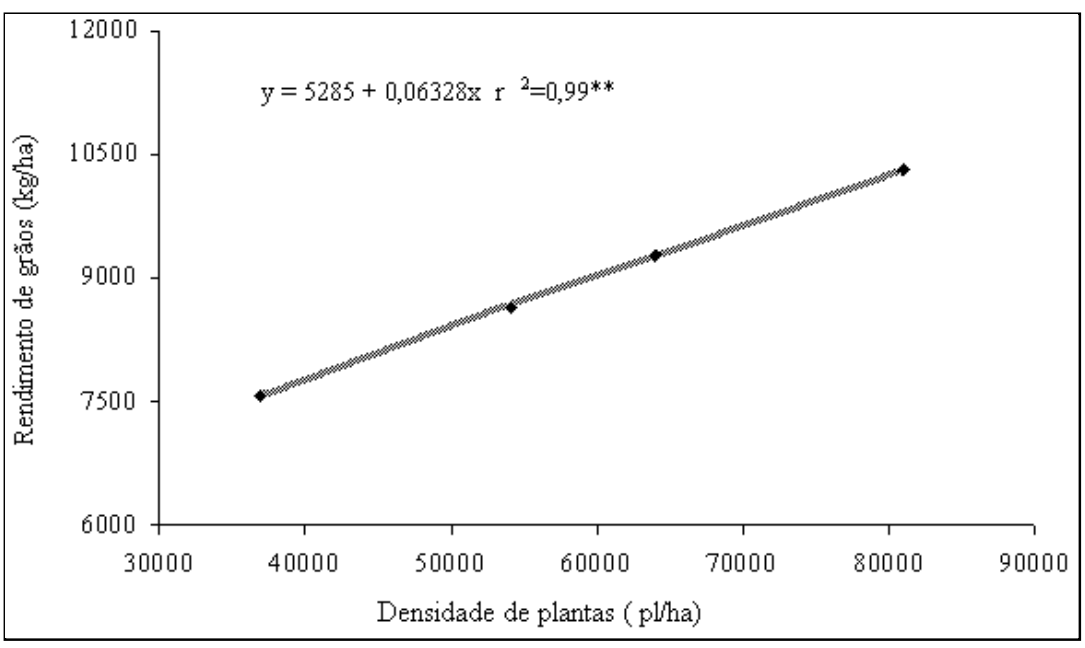

Figura 2 - Rendimento de grãos em função do aumento da densidade de plantas (Cargill 901), na média de dois espaçamentos entre linhas (1,0 e 0,75 m). Lages (SC), 1994/95.

\section{RESULTADOS E DISCUSSÃO}

Tendo em vista o objetivo principal deste trabalho, a apresentação dos resultados focalizará o potencial produtivo dos experimentos e os efeitos da densidade de plantas na sua obtenção. Dessa forma, discutir-se-á os tratamentos que apresentaram os maiores rendimentos de grãos, sem detalhar os efeitos individuais dos demais fatores avaliados nos experimentos.

A aptidão bioclimática do Planalto Catarinense à produção de milho enfatizada por SANGOI (1993) foi confirmada nos quatro experimentos realizados, onde os melhores tratamentos apresentaram rendimento médio de grãos superiores a $8.000 \mathrm{~kg} / \mathrm{ha}$ (figuras $1,2,3,4$ ). Essa produtividade supera facilmente a produtividade média catarinense e brasileira, que são de 3220 e $2440 \mathrm{~kg} \mathrm{ha}^{-1}$, respecti-

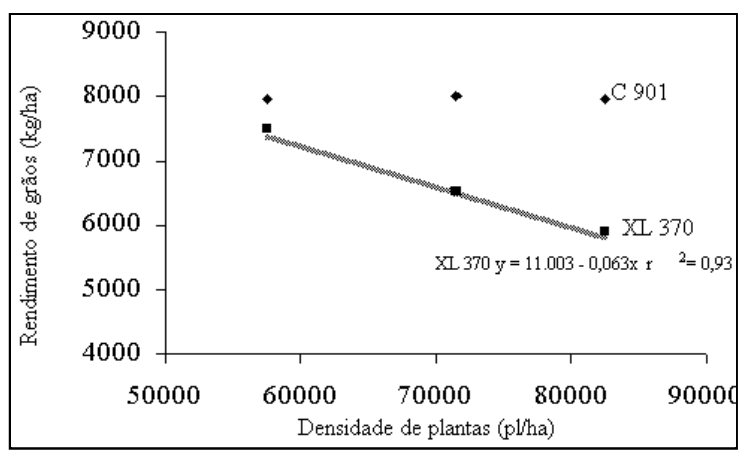

Figura 1 - Rendimento de grãos dos cultivares de milho (Cargill 901 e XL 370) em função da densidade de plantas, Lages, SC, 1993/94. vamente (ICEPA, 1995). Esse potencial produtivo elevado está intimamente relacionado com a resposta à densidade, à medida que a densidade ótima para a cultura do milho é tanto mais alta quanto maiores forem os tetos de rendimento (MUNDSTOCK, 1977; MUNDSTOCK e SILVA, 1989).

No experimento 1 , o aumento da densidade de plantas de 57.000 para $82.000 \mathrm{pl} /$ ha não proporcionou elevação no rendimento de grãos, considerando o cultivar mais produtivo (C 901) (figura 1). Isto possivelmente, deveu-se ao fato de se ter trabalhado apenas com três densidades, o que dificultou a caracterização matemática da resposta à densidade. Além disso, a ocorrência de um pequeno déficit hídrico durante o período de florescimento também pode ter contribuído para a ausência de resposta à densidade. Mesmo assim, obteve-se rendimento médio de grãos de $8.000 \mathrm{~kg} /$ ha para o cultivar C 901 . Nesse experimento, o número de espigas por planta não foi afetado pela população de plantas. Mesmo na densidade mais elevada, as plantas produziram 1,09 espigas por planta.

Para os demais experimentos, o aumento da densidade de plantas proporcionou incrementos no rendimento de grãos. No experimento 2, este aumento foi linear (figura 2), demonstrando o potencial da região para se trabalhar com densidades elevadas. Nesse experimento, o aumento da densidade de 35.000 para $80.000 \mathrm{pl} \mathrm{ha}^{-1}$ reduziu o número de espigas por planta em $28 \%$. No entanto, mesmo na densidade mais elevada, as plantas produziram 1,08 espigas por planta, o que determinou a obtenção de aproximadamente $10.500 \mathrm{~kg} / \mathrm{ha}$ de grãos. 
No experimento 3, a elevação da densidade de plantas determinou comportamento quadrático do rendimento de grãos quando a capina foi realizada durante todo o ciclo (figura 3). Considerando o rendimento de grãos, esse tratamento foi o mais eficiente no controle das plantas daninhas. Para esse tratamento, o máximo rendimento foi obtido na densidade de 68.000pl/ha. Diferentemente dos outros experimentos, que mesmo nas densidades mais elevadas apresentaram mais de uma espiga por planta, neste trabalho o uso de $80.000 \mathrm{pl} \mathrm{ha}^{-1}$ determinou a obtenção de um índice de espiga de 0,93 . A redução do número de espigas por planta da densidade mais baixa $\left(35.000 \mathrm{pl} \mathrm{ha}^{-1}\right)$ para a densidade mais alta $\left(80.000 \mathrm{pl} \mathrm{ha}^{-1}\right)$ foi de $24 \%$. Esse comportamento, possivelmente, deveu-se a fatores do ambiente (temperatura, umidade do solo, disponibilidade de nutrientes), já que nos experimentos 2 e 4 este mesmo cultivar produziu pelo menos uma espiga por planta, mesmo em densidades elevadas (mais de 80.000 $\left.\mathrm{pl} \mathrm{ha}^{-1}\right)$.

O comportamento do rendimento de grãos também foi quadrático no experimento 4 , considerando o tratamento com maior rendimento de grãos (emergência uniforme de plantas). O maior rendimento foi obtido na densidade de $80.000 \mathrm{pl} / \mathrm{ha}$ (figu-

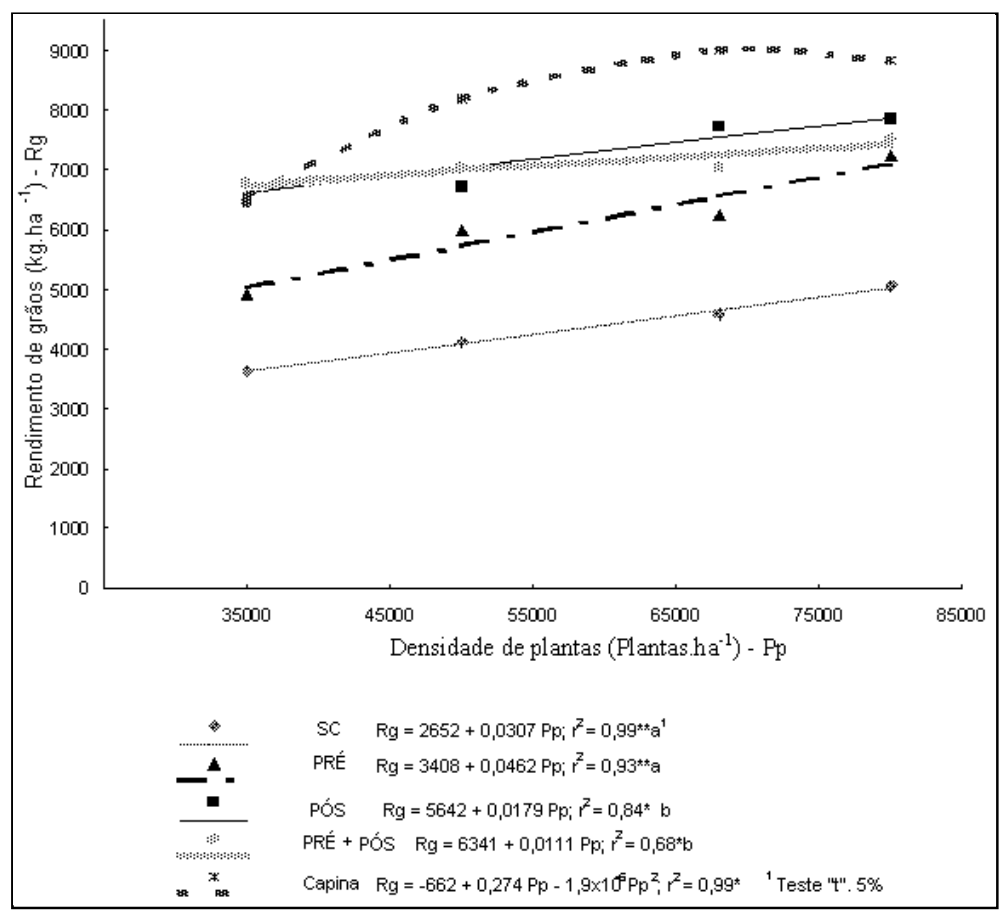

Figura 3 - Rendimento de grãos de milho (Cargill 901) em função do aumento da população de plantas e de diferentes métodos de controle de plantas daninhas $(\mathrm{SC}=$ sem controle; PRÉ = herbicida em pré-emergência; PÓS = herbicida em pós-emergência; PRÉ+PÓS = herbicida em pré e pós-emergência; capina $=$ capina manual). Lages $(\mathrm{SC}), 1995 / 96$. ra 4). Nesta densidade, o número de espigas por planta foi de 1,02. A redução do número de espigas foi de $8,1 \%$ entre a densidade mais baixa (40.000pl/ha) e a mais alta (100.000pl/ha), que apresentou 0,99 espiga por planta.

As mudanças na arquitetura dos cultivares de milho conferiram a estes uma maior capacidade de suportar a competição intra-específica e, deste forma, aumentou-se a produção de massa seca pela comunidade (TOLLENAR, 1991; SINCLAIR, 1998). Essas mudanças podem ser visualizadas através da comparação de trabalhos realizados com cultivares da década de 70 e 80 , com o cultivar utilizado nos quatro experimentos deste trabalho (C 901). Em trabalho realizado no Planalto Catarinense, SANGOI (1990) observou uma redução de 19,8\% no número de espigas por planta quando a densidade foi aumentada de 25.000 para $50.000 \mathrm{pl} / \mathrm{ha}$, na média de quatro materiais (Cargill 511, Agroceres 28, Empasc 151- Condá e Empasc 152 - Oeste). No entanto, o mais interessante está no fato de que na densidade de $50.000 \mathrm{pl} /$ ha só se obtiveram 0,89 espigas por planta, na média dos quatro materiais. MEDEIROS \& SILVA (1975) também obtiveram resultados semelhantes com o cultivar AG-28 na região da Depressão Central, RS. Nesse caso, o aumento da densidade de plantas de 35.000 para $80.000 \mathrm{pl} \mathrm{ha}^{-1}$ reduziu o número de espigas por planta de 0,97 para 0,77. Confrontando-se estes resultados com os índices de espiga obtidos nos quatro experimentos realizados com materiais de menor porte, pode-se verificar que as diferenças observadas foram consideráveis. $\mathrm{O}$ número de espigas produzidas por planta, mesmo em densidades próximas a $80.000 \mathrm{pl} \mathrm{ha}^{-1}$, ficou entre 0,93 e 1,09. Esses resultados corroboram as afirmações de TOLLENAR (1991) e SINCLAIR (1998) de que os materiais de milho de menor porte, de menor número de folhas e de folhas mais eretas apresentam maior capacidade de acumulação de MS na comunidade, sem com isso reduzirem drasticamente a emissão e manutenção das espigas pelas plantas.

A máxima densidade de plantas recomendada atualmente no estado de Santa Catarina para materiais superprecoces e precoces situase entre 50.000 a $60.000 \mathrm{pl} \mathrm{ha}{ }^{-1}$ (EPAGRI, 1997). Considerando os 


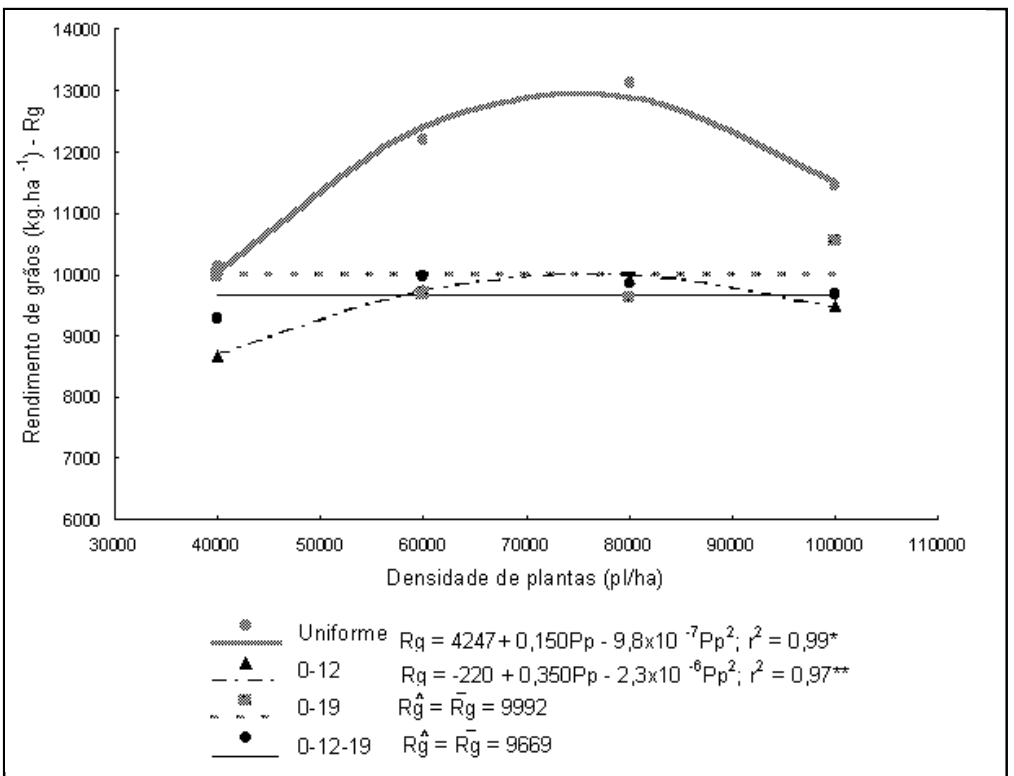

Figura 4 - Rendimento de grãos de milho (Cargill 901) em função do aumento da população de plantas e da desuniformidade de emergência (uniforme = emergência uniforme; $0-12=12$ dias de intervalo na emergência entre plantas adjacentes; 0-19 = 19 dias de intervalo na emergência entre plantas adjacentes; 0-12-19= 12 e 19 dias de intervalo na emergência entre plantas adjacentes. Lages (SC), 1996/97.

rendimentos obtidos pelo melhor tratamento de cada ensaio, na população que maximizou o rendimento de grãos dos experimentos que responderam à densidade de plantas (2, 3 e o 4), o uso de uma densidade de $55.000 \mathrm{pl} \mathrm{ha}^{-1}$ (representativa da população máxima recomendada) proporcionaria uma perda do potencial produtivo de $11 \%$, na média destes experimentos.

Através dos resultados obtidos, percebese que a utilização de cultivares de milho de menor porte pode ser acompanhada de aumentos na densidade de plantas, especialmente em lavouras de bom nível tecnológico e regiões com características climáticas semelhantes às do Planalto Catarinense. No entanto, é importante ressaltar que nas condições de elevada competição entre plantas aumenta a possibilidade de ocorrência de acamamento e quebra de plantas, bem como da incidência de grãos ardidos (EMATER/FEPAGRO-RS, 1998). Portanto, para que se possa usufruir dos benefícios da utilização de populações elevadas, é importante que se utilize cultivares com colmos fortes e boa sanidade de espigas.

O estudo do comportamento das plantas em comunidade e dos fatores que afetam o rendimento de grãos tem sido objeto de muitos trabalhos. Nesse sentido, ALMEIDA et al. (1998) apresentaram uma proposta de modelo de planta que seria mais eficiente em comunidade. Nessa proposta, os autores defendem a idéia de que para maximizar a exploração do ambiente é necessário que se disponha de plantas que tolerem a competição, investindo o mínimo em estruturas morfológicas e interferindo pouco sobre a performance dos seus vizinhos. Considerando essa proposição e os resultados obtidos nos experimentos descritos no presente trabalho, uma inferência pode ser feita, ou seja, que o menor porte das plantas, decorrente do menor crescimento vegetativo, do menor número de folhas e das folhas mais eretas (dados não apresentados), tenha proporcionado uma menor competição intra-específica, o que permitiu que a utilização de um maior número de indivíduos por área maximizasse o potencial produtivo da comunidade. Com base nessa inferência, pode se afirmar que a idéia de diminuição do porte das plantas, aliada à capacidade delas suportarem a competição, são características que ainda podem ser melhor exploradas, principalmente quando se pretende aumentar o potencial produtivo de grãos de milho.

\section{CONCLUSÃO}

Para locais de menor estação estival de crescimento, o uso de cultivares de menor porte pode ser acompanhado de um incremento na densidade de plantas até valores compreendidos entre 65 e $80.000 \mathrm{pl} \mathrm{ha}^{-1}$, desde que se tenha condições edáficas favoráveis, não ocorra déficit hídrico prolongado e o cultivar seja resistente ao acamamento.

\section{REFERÊNCIAS BIBLIOGRÁFICAS}

ALMEIDA, M.L. de, MUNDSTOCK, C.M., SANGOI, L. Conceito de ideotipo e seu uso no aumento do rendimento potencial de cereais. Ciência Rural, Santa Maria, v. 28, n. 2, p. 325-332, 1998.

ALMEIDA, M.L. de, SANGOI, L. Aumento da densidade de plantas de milho para regiões de curta estação estival de crescimento. Pesquisa Agropecuária Gaúcha, Porto Alegre, v. 2, n. 2 , p. $179-183,1996$.

CASAL, J.J., DEREGIBUS, V.A., SÁNCHEZ, R.A. Variations in tiller dynamics and morphology in Lolium multiflorum Lam. vegetative and reproductive plants as affected by differences in red/far-red irradiation. Annals of Botany, London, v. 56, p. 533-559, 1985. 
DWYER, L.M., TOLLENAR, M., STEWART, D.W. Changes in plant density dependence of leaf photosynthesis of maize (Zea mays L.) hybrids, 1959 to 1988. Canadian Journal Plant Science, Quebec, v. 71, p. 1-11, 1991.

EMATER/FEPAGRO-RS. Recomendações técnicas para a cultura do milho no estado do Rio Grande do Sul. Porto Alegre: FEPAGRO, 1998. 148 p. (Boletim Técnico, 5).

EMPASC. Zoneamento agroclimático do estado de Santa Catarina. Florianópolis: Empasc, 1978. 70 p.

EPAGRI. Recomendações técnicas para a cultura do milho em Santa Catarina. Florianópolis: Epagri, 1997. 59 p. (EPAGRI. Sistemas de Produção, 28).

FUNDAÇÃO INSTITUTO BRASILEIRO DE GEOGRAFIA E ESTATÍSITCA. Levantamento de recursos naturais. Rio de Janeiro: FIBGE, 1986. 791 p.

ICEPA. Síntese anual da agricultura de Santa Catarina. Florianópolis: ICEPA, 1995. 168 p.

JOHNSON, R.C., KEBEDE, H., MORNHINWEG, D.W. et al. Photosynthetic differences among Triticum accessions at tillering. Crop Science, Madison, v. 27, n. 5, p. 1046-1050, 1987.

KASELE, I.N., SHANAHAN, J.F., NIELSEN, D.C. Impact of growth retardants on corn leaf morphology and gas exchange traits. Crop Science, Madison, v. 35, n. 1, p. 190-194, 1995.

MEDEIROS, J.B., de, SILVA, P.R.F., da. Efeitos de níveis de nitrogênio e densidades de plantas sobre o rendimento de grãos e outras características agronômicas de duas cultivares de milho (Zea mays L.). Agronomia Sulriograndense, Porto Alegre, v. 11, n. 2, p. 227-249, 1975.

MEROTTO Jr, A., ALMEIDA., M.L. de, FUCKS, O. Aumento do rendimento de grãos de milho através do aumento da população de plantas. Ciência Rural, Santa Maria, v. 27, n. 4, p. 549-554, 1997a.

MEROTTO Jr., A., GUIDOLIN, A.F., ALMEIDA., M.L. de, $\boldsymbol{e}$ al. Aumento da população de plantas e uso de herbicidas no controle de plantas daninhas em milho. Planta Daninha, Londrina, v. 15, n. 2, p. 141-151, 1997b.

MORGAN J.A., LECAIN, D.R., WELLS, R. Semidwarfing genes concentrate photosynthetic machinery and affect leaf gas exchange of wheat. Crop Science, Madison, v. 30, n. 3, p. 602-608, 1990.

MUNDSTOCK, C.M. Densidade de semeadura de milho para o Rio Grande do Sul. Porto Alegre:UFRGS:ASCAR, 1977. 35 p (Boletim Técnico n. 1).

MUNDSTOCK, C.M., SILVA, P.R.F. da. Manejo da cultura do milho. Porto Alegre: UFRGS, 1989. 76 p. (Boletim Técnico 1).

PEIXOTO, C.M., SILVA, P.R.F. da, REZER, F., et al.. Produtividade de híbridos de milho em função da densidade de plantas, em dois níveis de manejo da água e da adubação. Pesquisa Agropecuária Gaúcha, Porto Alegre, v. 3, n. 1, p. 63-71, 1997.

RUSSEL, W.A. Genetic improvement of maize yields. Advances in Agronomy, Madison, v. 46, p. 245-298, 1991.

SANGOI, L. Comportamento de variedades e híbridos de milho em duas densidades de semeadura e dois níveis de fertilizantes. Pesquisa Agropecuária Brasileira, Brasília, v. 25, n. 12, p. 1715-1725, 1990.

SANGOI, L. Aptidão dos campos de Lages (SC) para produção de milho em diferentes épocas de semeadura. Pesquisa Agropecuária Brasileira, Brasília, v. 28, n. 1, p. 51-63, 1993.

SILVA, P.R.F., da. Determinação dos efeitos de quatro densidades no rendimento de grãos e características agronômicas, em seis cultivares de milho. Porto Alegre, 1972. 84 p. Dissertação (Mestrado em Agronomia ) - Fitotecnia, Faculdade de Agronomia, UFRGS, 1972.

SILVA, P.R.F. da, RIZZARDI, M., TREZZI, M.M., et al.. Densidade e arranjo de plantas em girassol. Pesquisa Agropecuária Brasileira, Brasília, v. 30, n. 6, p. 797-810, 1995.

SINCLAIR, T.R. Historical changes in harvest index and crop nitrogen accumulation. Crop Science, Madison, v. 38, n. 2, p. 638-643, 1998.

SOCIEDADE BRASILEIRA DE CIÊNCIA DO SOLOREGIONAL SUL. Recomendações de adubação e calagem para os estados do Rio Grande do Sul e Santa Catarina. 2. ed. Passo Fundo: SCBS/EMBRAPA - CNPT, 1989. 128 p.

UNIVERSIDADE FEDERAL DE SANTA MARIA. Levantamento de Reconhecimento dos Solos do Estado de Santa Catarina. Santa Maria: UFSM, 1972. 494 p.

Ciência Rural, v. 30, n. 1, 2000. 